\title{
OPTIMIZATION AND IN VITRO EVALUATION OF CREAMS FORMULATION CONTAINING SPIRULINA (ARTHROSPIRA PLATENSIS) EXTRACT AND ZINC OXIDE NANOPARTICLES
}

\author{
ERINDYAH RETNO WIKANTYASNING, KARTIKA FIDI ASTUTI, ULIL FIKRI NURHAKIMAH, \\ RAMADHANI DWI SULA
}

Department of Pharmaceutics, Faculty of Pharmacy, Universitas Muhammadiyah Surakarta, Surakarta, Indonesia. Email: erindyah.rw@ums.ac.id

\author{
Received: 16 March 2020, Revised and Accepted: 24 April 2020
}

\section{ABSTRACT}

Objective: The aims of this study are to formulate creams containing combination of spirulina (Arthrospira platensis) extract and zinc oxide nanoparticles using glycerol and propylene glycol as humectants and to evaluate their physical characteristics and in vitro antioxidant activity.

Methods: Spirulina was extracted by maceration method using methanol as solvent. The high energy ball milling technique was used to obtain zinc oxide nanoparticles. Creams were prepared in five formulas with the variations in the concentration of glycerol and propylene glycol. The physical characteristics of creams were evaluated including $\mathrm{pH}$, spreadability, adhesiveness, and viscosity. The optimization was conducted by Simplex Lattice Design (SLD) method using Design-Expert software. In vitro antioxidant activity was evaluated using DPPH method.

Results: The extraction resulted spirulina extract with a yield of $13.57 \%$. The particle size of the ZnO nanoparticles obtained was $143.4 \pm 0.364 \mathrm{~nm}$, with the polydispersity index of 0.177 . Optimum formula of cream was obtained with the concentration of glycerol and propylene glycol was 12.9 and $17.1 \%$, respectively. The spreadability, adhesiveness, viscosity, and $\mathrm{pH}$ of the optimized cream were $12.73 \pm 0.16 \mathrm{~cm}^{2}, 1.47 \pm 0.12 \mathrm{~s}, 126.67 \pm 5.77$ $\mathrm{dPas}$, and $7.11 \pm 0.04$, respectively. Cream containing spirulina extract and $\mathrm{ZnO}$ nanoparticles showed in vitro antioxidant activity with the $\mathrm{IC}_{50}$ value of $59.47 \pm 6.34 \mathrm{ppm}$.

Conclusion: Cream, containing spirulina and $\mathrm{ZnO}$ nanoparticles, was successfully prepared using glycerol and propylene glycol as humectant and showed very strong antioxidant activity in vitro.

Keywords: Zinc nanoparticles, Spirulina, Optimization, Humectant.

(C) 2021 The Authors. Published by Innovare Academic Sciences Pvt Ltd. This is an open access article under the CC BY license (http://creativecommons. org/ licenses/by/4.0/) DOI: http://dx.doi.org/10.22159/ijap.2021.v13s1.Y0096. Journal homepage: https://innovareacademics.in/journals/index.php/ijap

\section{INTRODUCTION}

Arthrospira platensis or well known as spirulina is blue-green algae that have many potential in medicinal, nutritional, or cosmetic application. The microalgae contain many nutritional compounds, such as proteins, vitamins, minerals, pigments, and enzymes [1,2]. Extracts of spirulina showed many activities, such as antibacterial [3], antioxidant [4,5], and anticancer [6]. The previous study reported the application of cosmetics containing spirulina using microneedle improved skin tone, skin hydration, and hyper-pigmentation of middle-aged women [7].

Various studies have shown that zinc has a protective effect against free radicals and induces the enzyme superoxide dismutase so that it can overcome oxidative stress due to the production of reactive oxygen species (ROS). Excessive ROS causes damage to skin tissue, such as skin aging [8]. Nanoparticle-sized cosmetic preparations have good biocompatibility and allow for specific interactions with biomolecules due to their relatively uniform size [9].

Cosmetic creams are commonly used to improve skin appearance and are one of the most preferred topical cosmetic preparations because they are easily applied to the skin. Cream type with oil in water or vanishing cream provides good appearance, easily applied, and cleaned. Glycerol and propylene glycol are needed as humectants which act by absorbing water from the environment or from cosmetic products and helping other substances to maintain water in the stratum corneum. The composition of glycerol and propylene glycol as humectants in cream preparations can affect skin hydration and physical characteristics of the preparations [10]. Glycerol is a natural compound and has a lower viscosity than propylene glycol [11]. The combination of glycerol with propylene glycol in topical cosmetic preparations may affect the physical properties of cream. Up to date, there are no studies on the formulation of creams containing spirulina extract and $\mathrm{ZnO}$ nanoparticles, using a combination of different humectants.

This study aimed to determine the effect of humectants, namely, glycerol and propylene glycol on the physical characteristics and in vitro antioxidant activity of cosmetic creams containing spirulina and $\mathrm{ZnO}$ nanoparticles.

\section{MATERIALS AND METHODS}

Materials

Spirulina powder was purchased from Cyanovit, Sukoharjo, Indonesia; Vitamin E, zinc oxide, 2,2-Diphenyl- 1-picrylhydrazyl (Sigma Aldrich), ethanol, methanol (Merck), glycerol, propylene glycol, stearic acid, triethanolamine, citric acid, cetyl alcohol, methylparaben, propylparaben, and rose oil (Brataco).

\section{Synthesis of ZnO nanoparticles}

The synthesis of $\mathrm{ZnO}$ nanoparticles referred to Salah et al. [12] using the high-energy milling method with modification. ZnO powder (50 g) was placed in an iron tube, and gourd 3/16 size (150 g) was added. The $\mathrm{ZnO}$ powder was then milled at a speed of $1000 \mathrm{rpm}$ for $10 \mathrm{~d}$ until nanoparticles were obtained. Characterization was carried out using the DLS system (Nanopartica SZ 100, Horiba) instrument by taking $10 \mathrm{mg}$ of $\mathrm{ZnO}$ samples which were dispersed in aquabidest and stirred for $5 \mathrm{~min}$. The morphology of nano $\mathrm{ZnO}$ was analyzed using SEM (SEMEDX JEOL JSM-6510LA). 
Extraction of $A$. platensis

Spirulina extract was obtained by the maceration method using methanol as solvent. Spirulina powder $(100 \mathrm{~g}$ ) was added in $1000 \mathrm{~mL}$ of methanol, then stirred for $5 \mathrm{~min}$, left for $24 \mathrm{~h}$, and stirred occasionally. The macerates were filtered with a Buchner funnel. The remaining powder was then macerated again. The re-maceration process was carried out twice. Macerates were collected and the solvent was evaporated using a rotary evaporator (Heidolph) to obtain the thick extracts of spirulina.

Preparation of creams containing spirulina extract and ZnO nanoparticles

Creams were formulated with different ratio of glycerol and propylene glycol (Table 1). The oil phase (stearic acid, cetyl alcohol, and propylparaben) was melted and mixed. The humectants and the water phase (citric acid, methylparaben, and TEA) were heated at $70 \pm 2^{\circ} \mathrm{C}$ under stirring. The oil phase was then added to the water phase and mixed until creamy and homogenous cream was formed. Spirulina extract (dissolved in $5 \mathrm{~mL}$ of ethanol) and $\mathrm{ZnO}$ nanoparticles (dispersed in $10 \mathrm{~mL}$ of distilled water) were then added to the cream base. After, the cream was continued stirring for cooling, and perfumes were added.

\section{Characterization of creams}

The physical characteristic of creams was evaluated including organoleptic, pH, viscosity, spreadability, and adhesiveness.

Creams were observed for the organoleptic characteristics, including texture, color, odor, and homogeneity.

The $\mathrm{pH}$ of creams was measured using $\mathrm{pH}$ meter (OHAUS) that was calibrated before.

The viscosity of the cream was evaluated using Viscotester (Rion-VT06) with rotor number two.

For the spreadability, $0.5 \mathrm{~g}$ of cream from each formulation was placed above the Petri dish and covered with the lid for $1 \mathrm{~min}$. The diameter of the cream was measured when given a load of 0,50 , and $100 \mathrm{~g}$.

The adhesiveness was tested by placing the gel $0.5 \mathrm{~g}$ on top of a glass object and then covered with another glass object. The load $500 \mathrm{~g}$ was

Table 1: Creams formulation containing spirulina extract and ZnO nanoparticles

\begin{tabular}{llllll}
\hline Ingredients & \multicolumn{3}{l}{ Weight percentage } & & \\
\cline { 2 - 6 } & F1 & F2 & F3 & F4 & F5 \\
\hline Spirulina extract & 2 & 2 & 2 & 2 & 2 \\
NanoZnO & 0.5 & 0.5 & 0.5 & 0.5 & 0.5 \\
Stearic acid & 12.5 & 12.5 & 12.5 & 12.5 & 12.5 \\
Triethanolamine & 2 & 2 & 2 & 2 & 2 \\
Cetyl alcohol & 3.5 & 3.5 & 3.5 & 3.5 & 3.5 \\
Citric acid & 0.2 & 0.2 & 0.2 & 0.2 & 0.2 \\
Glycerol & 10 & 12.5 & 15 & 17.5 & 20 \\
Propylene glycol & 20 & 17.5 & 15 & 12.5 & 10 \\
Methylparaben & 0.18 & 0.18 & 0.18 & 0.18 & 0.18 \\
Propylparaben & 0.02 & 0.02 & 0.02 & 0.02 & 0.02 \\
Rose oil & 0.3 & 0.3 & 0.3 & 0.3 & 0.3 \\
Distilled water & 48.8 & 48.8 & 48.8 & 48.8 & 48.8 \\
\hline
\end{tabular}

placed for $5 \mathrm{~min}$. The glass object was mounted on the device, and then, the time of the glass object released from each other was measured.

\section{Simplex lattice design analysis}

The responses of physical stability evaluation (pH, viscosity, adhesiveness, and spreadability) were analyzed to obtain the optimum levels of glycerol and propylene glycol that were able to provide the optimized formula with optimum cream properties. Data analysis was conducted using a Simplex Lattice Design method with Design Expert ${ }^{\circledR}$ software.

\section{Antioxidant activity}

The creams were evaluated for the free radical scavenging using DPPH method [13]. Cream $(0.1 \mathrm{~g})$ was placed in $50.0 \mathrm{~mL}$ of deionized water and stirred at $40^{\circ} \mathrm{C}$ for $1 \mathrm{~h}$. The supernatant was then diluted to make series of concentration. For each concentration, $0.5 \mathrm{~mL}$ of test solution was mixed with $0.5 \mathrm{~mL}$ of $0.4 \mathrm{mM}$ DPPH solution in ethanol. Ethanol p.a was added up to $1.5 \mathrm{~mL}$. The solution was incubated in the dark for $30 \mathrm{~min}$; then, the absorbance was recorded at $516 \mathrm{~nm}$ using UV-Vis spectrophotometer (Genesys 10S). Vitamin E solution was used as control. The percentage of free radical scavenging activity was calculated as followed:

$$
\% \text { Inhibition }=\frac{\text { Absorbance of DPPH }- \text { Absorbance of sample }}{\text { Absorbance of DPPH }}
$$

$\mathrm{IC}_{50}$ value was determined by the concentration of the sample required to scavenge $50 \%$ of DPPH free radicals.

\section{RESULTS AND DISCUSSION}

\section{Synthesis of ZnO nanoparticles}

ZnO nanoparticles were synthesized using HEM method with a yield of $77.7 \%$. The average particle size measured by PSA was $143.4 \pm 0.364$ $\mathrm{nm}$ with a PDI value of 0.177 . The previous studies reported that HEM technique produces $\mathrm{ZnO}$ nanoparticles in the range of 30-600 nm [14] or 200-800 nm [15]. SEM images of ZnO nanoparticles showed decreasing particle size after treatment with HEM, but there were a lot of aggregation of particles (Fig. 1).

All cream formulas were evaluated for organoleptic characteristics before further analysis. The results showed that the five cream formulas were soft, homogeneous, light brownish-green in color, and smelled of spirulina and rose oil. The physical characteristics of creams prepared are summarized in Table 2 .

The relationship between the proportions of glycerol and propylene glycol toward the physical characteristics of creams is summarized using a trace plot, as shown in Fig. 2, whereas the model equation was shown in Table 3.

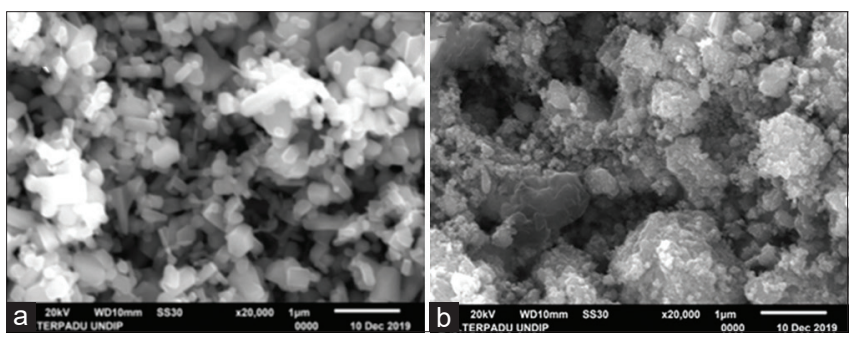

Fig. 1: SEM image of zinc oxide powder (a) and ZnO nanoparticles (b)

Table 2: Physical characteristics of creams containing spirulina extract and ZnO nanoparticles

\begin{tabular}{|c|c|c|c|c|}
\hline Formulation code & Spreadability ${ }^{\mathrm{a}}\left(\mathrm{cm}^{2} / \mathrm{g}\right)$ & Adhesiveness $^{\mathrm{a}}$ (s) & $\mathbf{p H}^{\mathrm{a}}$ & Viscosity $^{\mathrm{a}}$ (dPa.s) \\
\hline F1 & $12.88 \pm 0.85$ & $4.08 \pm 0.18$ & $6.91 \pm 0.23$ & $110 \pm 0.00$ \\
\hline F2 & $12.73 \pm 0.47$ & $1.53 \pm 0.32$ & $7.15 \pm 0.09$ & $180 \pm 0.00$ \\
\hline F3 & $12.19 \pm 1.85$ & $4.28 \pm 0.14$ & $7.33 \pm 0.05$ & $130 \pm 0.00$ \\
\hline $\mathrm{F} 4$ & $13.35 \pm 0.81$ & $1.67 \pm 0.03$ & $7.23 \pm 0.08$ & $80 \pm 0.00$ \\
\hline F5 & $13.13 \pm 0.08$ & $2.25 \pm 0.13$ & $7.47 \pm 0.11$ & $110 \pm 0.00$ \\
\hline
\end{tabular}

${ }^{\mathrm{a}}$ mean $\pm \mathrm{SD}, \mathrm{n}=3$ 


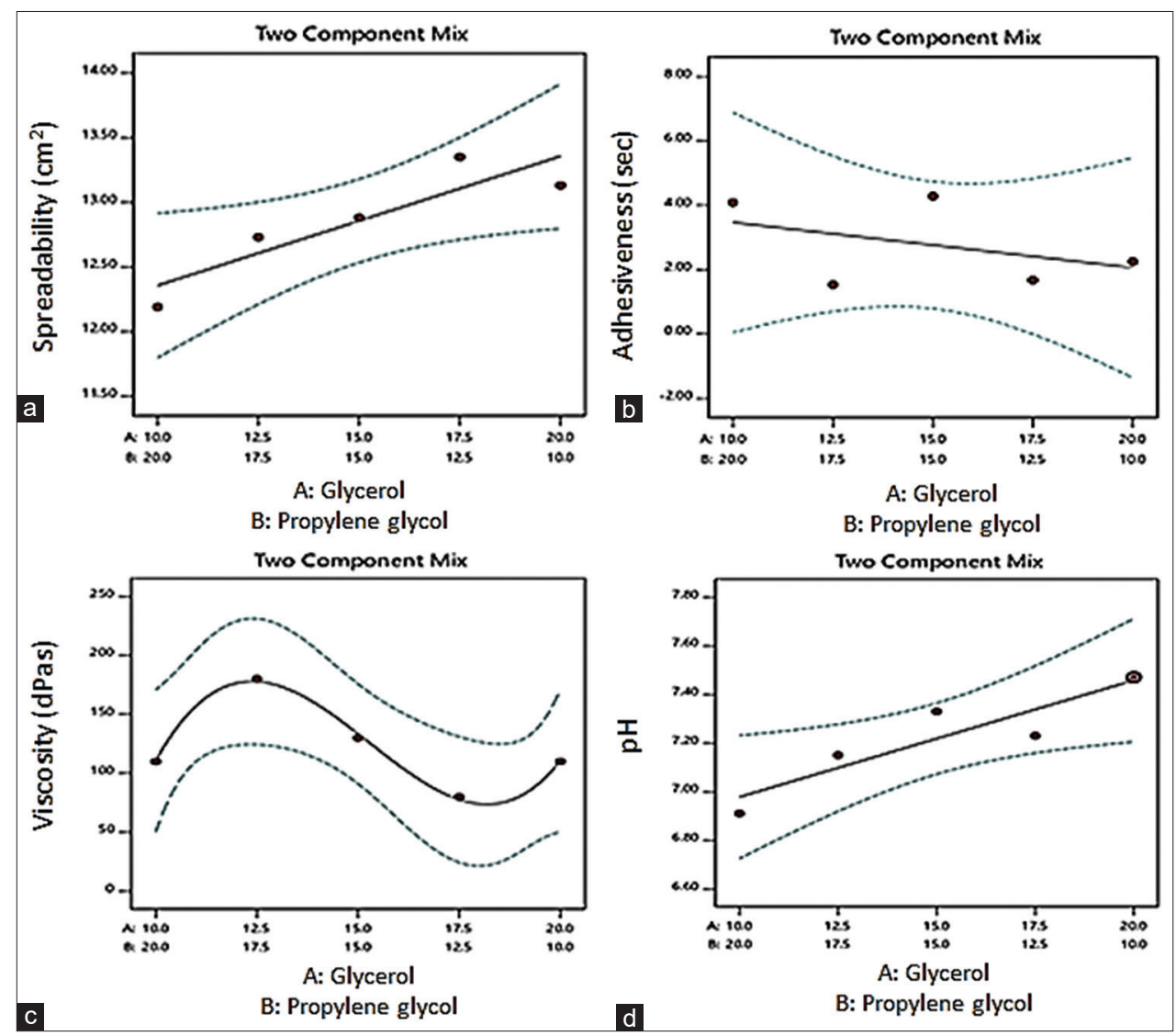

Fig. 2: Plot of glycerol and propylene glycol concentration on the spreadability (a), adhesiveness (b), viscosity (c), and pH (d)

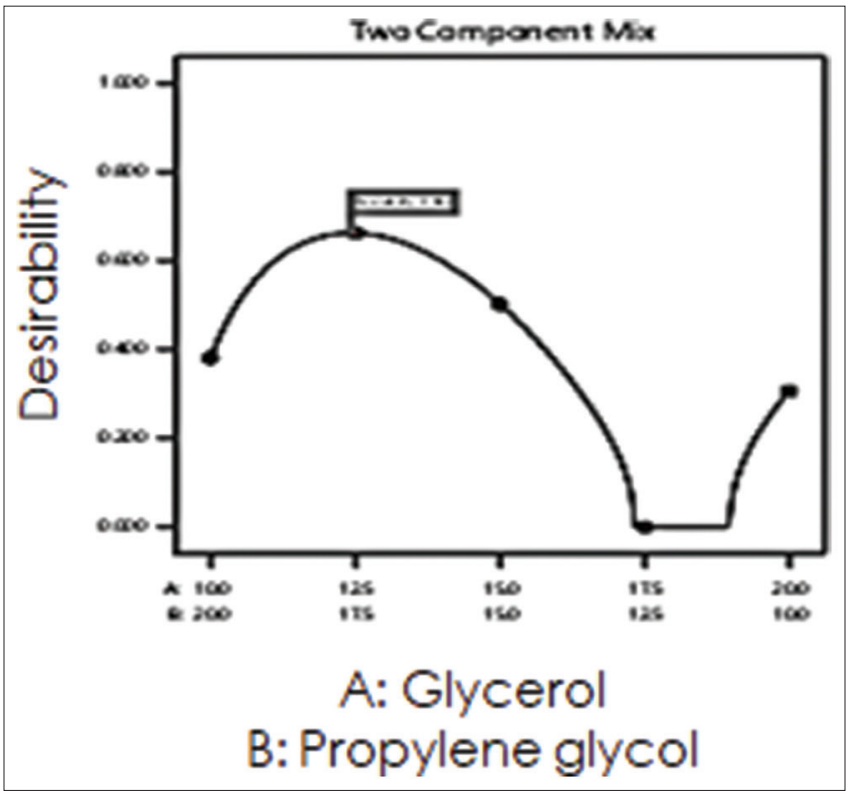

Fig. 3: Contour plot of optimized formula using SLD approach

The trace plots of spreadability (Fig. 2a) showed a significant linear curve $(\mathrm{p}<0.05)$, indicated that increasing glycerol concentration increased the spread of cream on the skin. Glycerol affected the spreadability more than propylene glycol (Table 3), probably due to the lower viscosity of glycerol compared to propylene glycol [11].

Fig. $2 \mathrm{~b}$ shows the creams adhesiveness in the presence of glycerol and propylene glycol which were in the range of 1.53-4.28 s. The graph was a mean-shaped model, with $p>0.05$, indicated an insignificant
Table 3: Predicted model equations of the creams responses using SLD approach

\begin{tabular}{llll}
\hline Graphic & Response & Equation & Model \\
\hline A & Spreadability & $\mathrm{Y}=13.36 \mathrm{~A}+12.36 \mathrm{~B}$ & Linear \\
$\mathrm{B}$ & Adhesiveness & $\mathrm{Y}=2.06 \mathrm{~A}+3.47 \mathrm{~B}$ & Mean \\
C & Viscosity & $\mathrm{Y}=110.57 \mathrm{~A}+110.57 \mathrm{~B}+91.43 \mathrm{AB}$ & Cubic \\
$\mathrm{D}$ & $\mathrm{pH}$ & $\mathrm{Y}=7.46 \mathrm{~A}+6.98 \mathrm{~B}$ & Linear \\
\hline
\end{tabular}

Table 4: $\mathrm{IC}_{50}$ and antioxidant activity of samples

\begin{tabular}{llll}
\hline Sample & IC $_{\mathbf{5 0}}{ }^{*}$ & AAI** & $\begin{array}{l}\text { Antioxidant } \\
\text { activity }\end{array}$ \\
\hline $\begin{array}{l}\text { Vitamin E } \\
\text { Cream base }\end{array}$ & $1.413 \pm 1.019$ & $148.087 \pm 75.589$ & Very strong \\
$\begin{array}{l}\text { Spirulina } \\
\text { extract }\end{array}$ & $35.153 \pm 2.990$ & $4.510 \pm 0.397$ & Weak \\
$\begin{array}{l}\text { Optimized } \\
\text { cream }\end{array}$ & $59.470 \pm 6.344$ & $2.673 \pm 0.301$ & Very strong \\
\hline
\end{tabular}

${ }^{*} \mathrm{C}_{50}$ : Concentration of sample required to scavenge $50 \%$ of DPPH free radicals. **AAI: Antioxidant activity index

model. Only formulas 2 and 3 met the required adhesion value of more than $4 \mathrm{~s}$.

The viscosity model graph is cubic (Fig. 2c) with the equation, as shown in Table 3. Statistical ANOVA analysis showed $\mathrm{p}>0.05$, indicated there was no significant effect of humectant ratio toward viscosity. The coefficients of A and B indicated that both compounds affected the viscosity of the creams. The coefficient of $\mathrm{AB}$ with a positive value $(+91.43)$ showed that there was an interaction between glycerol and propylene glycol which increased the creams viscosity. 
The $\mathrm{pH}$ of formulated creams was in the range of 6.91-7.47 and showed a linear correlation (Fig. 2d). Glycerol affected the creams pH more than propylene glycol. Increasing glycerol concentration increased the $\mathrm{pH}$ of creams.

SLD analysis resulted an optimized formula at the ratio of glycerol and propylene glycol of 12.9: 17.1 with a desirability value of 0.664 (Fig. 3).

The antioxidant activity of Vitamin E, spirulina extract, cream base, and the optimized cream was evaluated using DPPH method (Table 4). All samples except for the cream base exhibited strong antioxidant activities.

Spirulina extract showed high levels of RSA (Radical Scavenging Activity) [14]. The antioxidant activity of spirulina is produced from phenolic and phycocyanin compounds contained in spirulina. Some compounds in spirulina such as phycobilin (C-phycocyanin, allophycocyanin, and C-phycoerytherin), phenolic (pyrogallol), and flavonoid (catechin) pigments can produce great antiradical activity [17]. The result was also supported by previous study that zinc oxide nanoparticles showed good scavenging activity $[18,19]$

\section{CONCLUSION}

From this study, it can be concluded that glycerol and propylene glycol affect the physical characteristics of the cream preparations. The ratio of glycerol and propylene glycol concentrations at 12.9:17.1 \%w/w produced optimized cream and exhibited antioxidant activity with a very strong category in $\mathrm{IC}_{50}$ value of $59.47 \pm 6.34 \mathrm{ppm}$

\section{CONFLICTS OF INTEREST}

All authors have none to declare

\section{REFERENCES}

1. Hoseini S, Khosravi-Darani K, Mozafari M. Nutritional and medical applications of Spirulina microalgae. Mini Rev Med Chem 2013;13:1231-7.

2. Shabana E, Gabr M, Moussa H, El-Shaer E. Biochemical composition and antioxidant activities of Arthrospira (Spirulina) platensis in response to gamma irradiation. Food Chem 2017;214:550-5.

3. Bhuvaneswari G, Shukla S, Makesh M, Sudhagar S, Kothari D, Singh A. Antibacterial activity of Spirulina (Arthrospira platensis Geitler) against bacterial pathogens in aquaculture. Isr J Aquac 2013;65:1-8.
4. Khan A, Iqbal Z, Rehman Z, Nasira F, Khana A. Ismail M, et al. Application of SeDeM Expert system in formulation development of effervescent tablets by direct compression. Saudi Pharm J 2014;22:433-44.

5. Bashandy S, El Awdan S, Ebaid H, Alhazza IM. Antioxidant potential of Spirulina platensis mitigates oxidative stress and reprotoxicity induced by sodium arsenite in male rats. Oxid Med Cell Longev 2016;2016:1-8.

6. Konícková R, Vanková K, Vaníková J, Vánová K, Muchová L. Anticancer effects of blue-green alga Spirulina platensis, a natural source of bilirubin-like tetrapyrrolic compounds. Ann Hepatol 2014;13:273-83.

7. Jung S, Lee H, Li S. A study on the effect of Spirulinacontaining cosmetics using micro-needle. J Korea Acad Coop Soc 2017; 18:269-76.

8. Prasad A. Zinc: An antioxidant and anti-inflammatory agent: Role of zinc in degenerative disorders of aging. J Trace Elem Med Biol 2014;28:364-71.

9. Mirzaei H, Darroudi M. Zinc oxide nanoparticles: Biological synthesis and biomedical applications. Ceram Int 2017;43:907-14.

10. Moldovan M, Ciortea L. Efficacy evaluation of different cream formulations on healthy skin properties quality control of pharmaceuticals view project. Farmacia 2010;58:787-94.

11. Rowe CR, Sheskey PJ, Quinn ME. Handbook of Pharmaceutical Excipients. $6^{\text {th }}$ ed. London: Phamaceutical Press; 2009.

12. Salah N, Habib S, Khan Z, Memic A, Azam A, Alarfaj E, et al. Highenergy ball milling technique for $\mathrm{ZnO}$ nanoparticles as antibacterial material. Int J Nanomed 2011;6:863-9.

13. Blois MS. Antioxidant determinations by the use of a stable free radical. Nature 1958;181:1199-200.

14. Salah N, Habib SS, Khan ZH, Memic A, Azam A, Alarfaj E, et al. Highenergy ball milling technique for $\mathrm{ZnO}$ nanoparticles as antibacterial material. Int J Nanomed 2011;6:863-9.

15. Zhang Y, Chen Y, Westerhoff P, Hristovski K, Crittenden JC. Stability of commercial metal oxide nanoparticles in water. Water Res 2008;42:2204-12.

16. Golmakani M, Moosavi-Nasab M, Keramat M, Mohammadi M. Arthrospira platensis extract as a natural antioxidant for improving oxidative stability of common kilka (Clupeonella cultriventris caspia) Oil. Turk J Fish Aquat Sci 2018;18:1315-23.

17. Shalaby EA, Shanab SM. Comparison of DPPH and ABTS assays for determining antioxidant potential of water and methanol extracts of Spirulina platensis. Indian J Mar Sci 2013;42:556-64.

18. Aswathy R, Gabylis B, Anwesha S, Bhaskara RK. Green synthesis and characterization of marine yeast-mediated silver and zinc oxide nanoparticles and assessment of their antioxidant activity. Asian J Pharm Clin Res 2017;10:235-40.

19. Jacob V, Rajiv P. In vitro analysis: The antimicrobial and antioxidant activity of zinc oxide nanoparticles from Curcuma longa. Asian J Pharm Clin Res 2019;12:200-4. 